\title{
Sintesis Nanopartikel Magnesium Oksida (MgO) dengan Metode Presipitasi
}

\author{
Novia Alvionita*, Astuti \\ Jurusan Fisika FMIPA Universitas Andalas \\ Kampus Unand, Limau Manis, Padang, 25163 \\ *noviaalvionita30@gmail.com
}

\begin{abstract}
ABSTRAK
Telah dilakukan sintesis nanopartikel Magnesium Oksida (MgO) dengan metode presipitasi. Nanopartikel MgO disintesis menggunakan Polietilen Glikol (PEG) yaitu PEG 2000 (sampel 1), PEG 4000 (sampel 2), dan PEG 6000 (sampel 3) sebagai template dengan suhu sintering $600{ }^{\circ} \mathrm{C}$ selama 3 jam. Sampel dikarakterisasi dengan menggunakan X-Ray Diffraction (XRD) untuk mengetahui ukuran dan struktur kristal, sedangkan Scanning Electron Microscopy (SEM) digunakan untuk mengidentifikasi morfologi permukaan sampel. Hasil karakterisasi XRD menunjukkan bahwa ukuran kristal pada sampel 1, sampel 2 dan sampel 3 berturut-turut adalah 66,76 nm, 74,15 nm, dan 66,79 nm. Hasil SEM menunjukkan bahwa masih terdapat penggumpalan (aglomerasi) antar partikel $\mathrm{MgO}$ pada ketiga sampel. Semakin besar berat molekul PEG, maka semakin besar pula persentase puncak nanopartikel $\mathrm{MgO}$ yang dihasilkan. Kata kunci: nanopartikel $\mathrm{MgO}$, polietilen glikol, presipitasi
\end{abstract}

ABSTRACT

The synthesis of Magnesium Oxide $(\mathrm{MgO})$ nanoparticles by using precipitation method has been done. $\mathrm{MgO}$ nanoparticles were synthesized by using polyethylene glycol (PEG) 2000 (sample 1), PEG 4000 (sample 2), and PEG 6000 (sample 3) as template at sintering temperature of $600{ }^{\circ} \mathrm{C}$ for 3 hours. The crystal size and structure were characterized using X-Ray Diffraction (XRD), whereas the surface morfology was characterized using Scanning Electron Microscopy (SEM). The XRD results indicate that the crystal size of sample 1, sample 2 and sample 3 are $66.76 \mathrm{~nm}, 74.15 \mathrm{~nm}$ and $66.79 \mathrm{~nm}$, respectively. The SEM images indicate that there are still agglomeration between the particles of $\mathrm{MgO}$ for all samples. The larger molecular weight of PEG, the higher the percentage of $M g O$ nanoparticles with respect to the peak.

Keywords: $\mathrm{MgO}$ nanoparticles, polyethylene glycol, precipitation

\section{PENDAHULUAN}

Nanoteknologi adalah ilmu atau rekayasa dalam menciptakan material, struktur fungsional maupun piranti dalam ukuran nanometer (Abdullah, 2009). Salah satu material yang berpotensi untuk dikembangkan dalam nanoteknologi adalah logam oksida. Logam oksida sangat penting dalam bidang kimia, fisika, dan material, karena memiliki kelebihan antara lain permitivitas listrik tinggi, tidak beracun, stabil dan aktivitas fotokatalisnya tinggi (Ganapathi dkk., 2013). Logam oksida yang banyak diteliti saat ini antara lain Titanium Dioksida $\left(\mathrm{TiO}_{2}\right)$, Seng Oksida $(\mathrm{ZnO})$, Magnetit $\left(\mathrm{Fe}_{3} \mathrm{O}_{4}\right)$, Aluminium Oksida $\left(\mathrm{Al}_{2} \mathrm{O}_{3}\right)$, Silikon Dioksida $\left(\mathrm{SiO}_{2}\right)$, dan Magnesium Oksida (MgO).

$\mathrm{MgO}$ merupakan bahan keramik yang potensial. $\mathrm{MgO}$ merupakan bahan keramik yang mempunyai titik lebur yang tinggi, sehingga bersifat tahan api, permukaan yang kuat, tahan air, kedap suara, tahan terhadap serangan jamur, lumut dan pembusukan. $\mathrm{MgO}$ biasanya digunakan pada pembuatan material sebagai dinding tahan panas pada furnace, isolator listrik, pembungkus makanan, kosmetik dan pembuatan obat pada bidang farmasi (Klabunde, 2001).

Sintesis nanopartikel $\mathrm{MgO}$, dapat dilakukan dengan metode presipitasi, sol-gel, dan hidrotermal. Masing-masing metode tersebut memiliki kelebihan dan kekurangan. Metode hidrotermal dapat mengurangi aglomerasi partikel dan menghasilkan kristal dengan ukuran relatif seragam dan homogen pada temperatur rendah (di bawah $150{ }^{\circ} \mathrm{C}$ ). Metode ini, sayangnya, mahal dan stoikoimetri larutan sulit untuk dikontrol (Witjaksono, 2011). Metode presipitasi memungkinkan kontrol atas ukuran partikel sehingga waktu yang dibutuhkan relatif singkat dan dapat dilakukan pada suhu rendah.

Meenakshi dkk. (2012), meneliti nanopartikel $\mathrm{MgO}$ yang disintesis dengan metode presipitasi menggunakan PVP (Polivinilpirolidone). Berdasarkan analisis data XRD, MgO yang dihasilkan memiliki ukuran kristal $20 \mathrm{~nm}$ dengan struktur kristal heksagonal. Hasil SEM 
menunjukkan bahwa morfologi permukaan partikel tidak homogen dan terdapat aglomerasi. Ganapathi dkk. (2013) juga telah meneliti struktur nanopartikel $\mathrm{MgO}$ dengan metode sintesis kopresipitasi. Hasil analisis XRD dan SEM menunjukkan bahwa partikel berbentuk bulat dengan ukuran $21 \mathrm{~nm}$. Selain itu, Alpionita dan Astuti (2015) juga melakukan penelitian tentang sintesis dan karakterisasi MgO dengan variasi massa PEG 6000 yaitu 0,5 g, $1 \mathrm{~g}, 1,5 \mathrm{~g}, 2 \mathrm{~g}$ dan variasi suhu sintering yaitu $350{ }^{\circ} \mathrm{C}$ dan $500{ }^{\circ} \mathrm{C}$. Sintesis nanopartikel $\mathrm{MgO}$ dilakukan dengan metode presipitasi. Hasil analisis XRD menunjukkan bahwa ukuran kristal optimum diperoleh dengan penambahan massa PEG 2 g yaitu $72 \mathrm{~nm}$, karena puncak difraksi yang dihasilkan lebih tinggi dibandingkan dengan penambahan massa PEG yang lebih kecil. Ukuran kristal yang terkecil pada penambahan massa PEG $1 \mathrm{~g}$ yaitu $61 \mathrm{~nm}$ dan struktur kristal kubik. Hasil analisis SEM menunjukkan bahwa dengan suhu sintering $350{ }^{\circ} \mathrm{C}$ morfologi permukaan partikel kurang homogen dan terdapatnya rongga-rongga antara partikel, dan pada suhu sintering $500{ }^{\circ} \mathrm{C}$ morfologi permukaan partikel terdapat sedikit penggumpalan, sehingga suhu sintering $500{ }^{\circ} \mathrm{C}$ lebih optimum dibandingkan suhu sintering $350^{\circ} \mathrm{C}$.

Berdasarkan penelitian yang telah dilakukan sebelumnya terdapat beberapa kelemahan yaitu morfologi permukaan partikel kurang homogen, masih terdapat penggumpalan partikel. Oleh sebab itu, untuk mengurangi kelemahan dari penelitian sebelumnya maka pada penelitian ini akan disintesis nanopartikel $\mathrm{MgO}$ menggunakan tiga jenis PEG dengan metode presipitasi. Hasil sintesis nanopartikel MgO dikarakterisasi menggunakan XRD dan SEM. Penelitian ini bertujuan untuk melihat pengaruh jenis PEG terhadap ukuran kristal, kehomogenan partikel dan mengurangi penggumpalan partikel.

\section{METODE}

Nanopartikel $\mathrm{MgO}$ disintesis menggunakan metode presipitasi dengan penambahan PEG yaitu PEG 2000, PEG 4000, dan PEG 6000. $\mathrm{MgNO}_{3} 1 \mathrm{M}$ sebanyak $50 \mathrm{~mL}$ dicampurkan dengan PEG (2 g) kemudian diaduk menggunakan magnetic stirrer selama 10 menit pada suhu kamar. Selanjutnya larutan $\mathrm{NaHCO}_{3} 1 \mathrm{M}$ sebanyak $50 \mathrm{~mL}$ ditambahkan ke dalam $\mathrm{MgNO}_{3}$ dan PEG yang telah dicampurkan sebelumnya dan diaduk dengan kecepatan konstan. Larutan $\mathrm{NaOH} 1 \mathrm{M}$ sebanyak $50 \mathrm{~mL}$ ditambahkan ke dalam campuran larutan sebelumnya dan diaduk selama 3 jam tanpa mengubah parameter apapun. Setelah itu hasilnya akan berbentuk bubuk endapan putih $\mathrm{MgO}$, lalu disaring dengan menggunakan kertas saring. Hasil penyaringan tersebut dicuci dengan air suling ganda untuk membuat endapan yang bebas dari unsur asing dan menghasilkan substrat $\mathrm{Mg}(\mathrm{OH})_{2}$. Kemudian $\mathrm{Mg}(\mathrm{OH})_{2}$ dikeringkan dengan menggunakan oven selama 1 jam pada suhu $80{ }^{\circ} \mathrm{C}$ dan disintering selama 3 jam pada suhu $600{ }^{\circ} \mathrm{C}$ menggunakan furnace (Meenakshi dkk., 2012).

\section{HASIL DAN DISKUSI}

\subsection{Hasil karakterisasi XRD}

Puncak-puncak yang didapatkan dari XRD dicocokkan dengan International Centre for Diffraction Data (ICDD). Puncak-puncak difraksi yang dihasilkan pada sampel 1, sampel 2, dan sampel 3 ditunjukkan pada Gambar 1.

Berdasarkan pola difraksi sinar-X pada Gambar 1(a), terlihat puncak tertinggi yaitu puncak $\mathrm{MgO}$ dengan posisi $2 \theta=42,859^{\circ}$. Puncak-puncak difraksi yang muncul yaitu lima puncak $\mathrm{MgO}$, satu puncak $\mathrm{Na}_{2} \mathrm{CO}_{3}$ dan lima puncak $\mathrm{NaNO}_{3}$, tetapi ada puncak $\mathrm{MgO}$ dengan $\mathrm{NaNO}_{3}$ berada di posisi yang sama yaitu pada posisi $2 \theta=62,2448^{\circ}, 74,6459^{\circ}$, dan $93,9501^{\circ}$. $\mathrm{MgO}$ memiliki struktur kristal kubik dengan parameter kisi yaitu $a=b=c=4,216 \AA$ dan $\alpha=\beta=\gamma=90^{\circ}$. Ukuran kristal dari sampel 1 dihitung dengan menggunakan Persamaan Scherrer. Berdasarkan dari alat XRD $\lambda=1,56060 \AA$, dan setelah dilakukan approximasi dengan menggunakan Persamaan Scherrer $k=0,9, \theta=21,4295^{\circ}$, FWHM (Full Width of Half Maximum) $=0,2558^{\circ}$, dan $B=2,23114 \times 10^{-3} \mathrm{rad}$, sehingga ukuran kristal $\mathrm{MgO}$ yang didapatkan $66,76 \mathrm{~nm}$.

Gambar 1(b) merupakan pola difraksi untuk sampel 2. Pada Gambar 1(b) dihasilkan 10 puncak, yaitu lima puncak $\mathrm{MgO}$, empat puncak $\mathrm{NaNO}_{3}$, dan satu puncak $\mathrm{Na}_{2} \mathrm{CO}_{3}$. Puncak difraksi $\mathrm{MgO}$ dengan $\mathrm{NaNO}_{3}$ juga berhimpit pada posisi sudut $=62,2298^{\circ}$ dan 93,890. . Puncak tertinggi yang dihasilkan yaitu $\mathrm{MgO}$ dengan posisi $2 \theta=42,858^{\circ} . \mathrm{MgO}$ menghasilkan struktur 
kristal kubik dengan parameter kisi $a=b=c=4,217 \AA$ dan $\alpha=\beta=\gamma=90^{\circ}$. FWHM puncak tertinggi adalah $0,2303^{\circ}, \theta=21,42945^{\circ}$, dan $B=2,00872 \times 10^{-3} \mathrm{rad}$, sehingga ukuran kristal yang didapatkan 74,15 nm. Ukuran kristal $\mathrm{MgO}$ pada sampel 2 lebih besar dibandingkan sampel 1 .

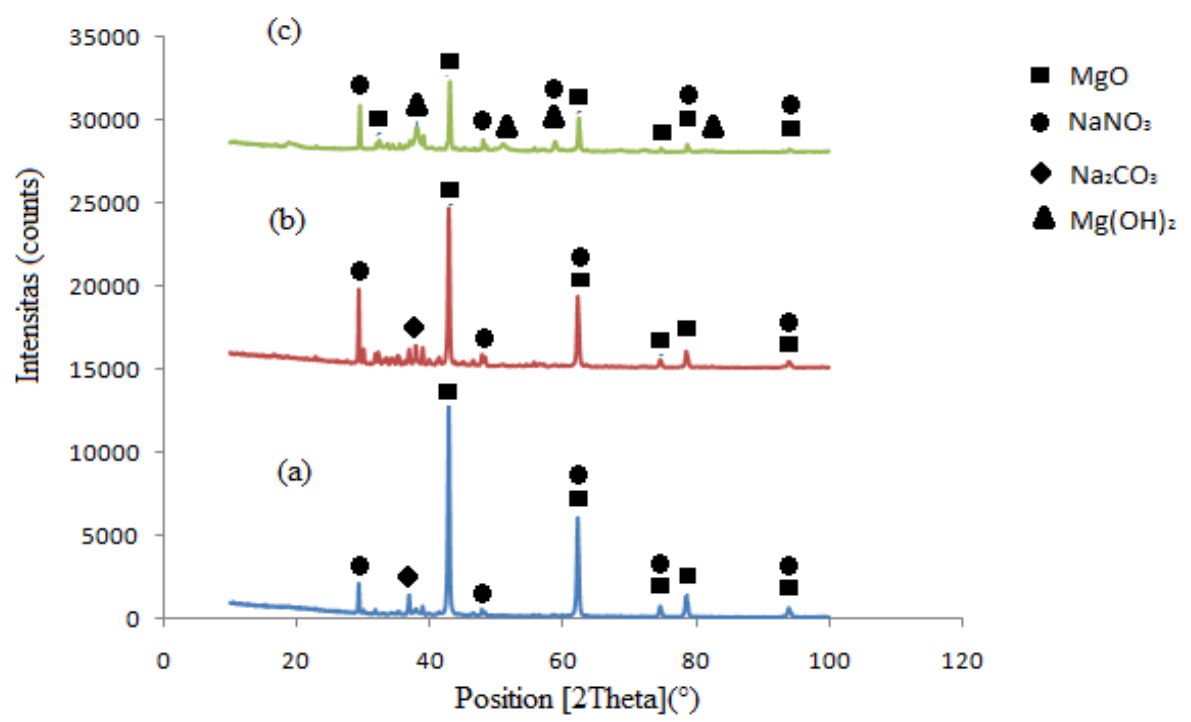

Gambar 1 Pola difraksi sinar-X pada (a) sampel 1, (b) sampel 2, dan (c) sampel 3

Gambar 1 (c) merupakan pola difraksi sampel 3. Pada Gambar 1(c) terlihat bahwa puncak tertinggi yang dihasilkan yaitu $\mathrm{MgO}$ dengan posisi $2 \theta=43,024^{\circ}$, struktur kristal yang dihasilkan kubik dengan parameter kisi $a=b=c=4,209 \AA$ dan $\alpha=\beta=\gamma=90^{\circ}$. Pada sampel 3 posisi sudut dan parameter kisi yang didapatkan berbeda dari sampel 1 dan sampel 2. Hal ini disebabkan karena pada sampel 3 berat molekul PEG yang digunakan lebih besar dibandingkan dengan sampel 1 dan sampel 2. Ukuran kristal yang didapatkan yaitu 66,79 nm. Ukuran kristal sampel 3 dan sampel sama, karena puncak tertinggi $\mathrm{MgO}$ dari sampel 1 dan sampel 3 memiliki nilai FWHM yang sama yaitu $0,2558^{\circ}$. Berbeda dengan sampel 2, ukuran kristal yang didapatkan lebih besar yaitu 74,15 nm, karena sampel 2 memiliki nilai FWHM $=0,2303^{\circ}$. Pada sampel 3 terdapat Magnesium Hidroksida $\left(\mathrm{Mg}(\mathrm{OH})_{2}\right)$, berbeda dengan sampel 1 dan sampel 2 yang tidak terdapat $\mathrm{Mg}(\mathrm{OH})_{2}$. Hal ini dapat disebabkan karena $\mathrm{MgO}$ bersifat mudah menguap sehingga terjadi perubahan fasa $\mathrm{MgO}$ menjadi $\mathrm{Mg}(\mathrm{OH})_{2}$.

Karakterisasi XRD menunjukkan bahwa persentase $\mathrm{MgO}$ pada sampel 3 sebesar 66,6 \%, sampel 2 sebesar $50 \%$ dan sampel 1 sebesar 45,4\%. Sampel 3 memiliki persentase $\mathrm{MgO}$ paling tinggi dari ketiga sampel. Hal ini ditandai dengan jumlah puncak $\mathrm{MgO}$ yang dihasilkan pada sampel 3 lebih banyak dari sampel 1 dan sampel 2.

\subsection{Hasil karakterisasi SEM}

Karakterisasi menggunakan SEM dilakukan dengan pembesaran 10.000 kali. Berdasarkan hasil karakterisasi SEM, bentuk morfologi permukaan yang dihasilkan pada sampel 1, sampel 2 dan sampel 3 berbeda-beda. Hasil karakterisasi SEM untuk sampel 1, sampel 2, dan sampel 3 dapat dilihat pada Gambar 2.

Gambar 2(a) menunjukkan bentuk morfologi permukaan sampel 1 dengan menggunakan PEG 2000. Morfologi permukaaan partikel lebih homogen dibandingkan sampel 2 dan sampel 3. Pada sampel 1 partikel-partikel kurang terlihat dengan jelas, karena pembesaran alat yang terbatas sehingga sulit untuk menentukan ukuran partikel $\mathrm{MgO}$.

Pada Gambar 2(b) merupakan morfologi permukaan sampel 2. Pada sampel 2 terlihat terdapat bongkohan-bongkahan akibat aglomerasi antar partikel, sedangkan Gambar 2(c) adalah morfologi permukaan sampel 3. Morfologi permukaan yang dihasilkan sampel 3 sama dengan sampel 2. 


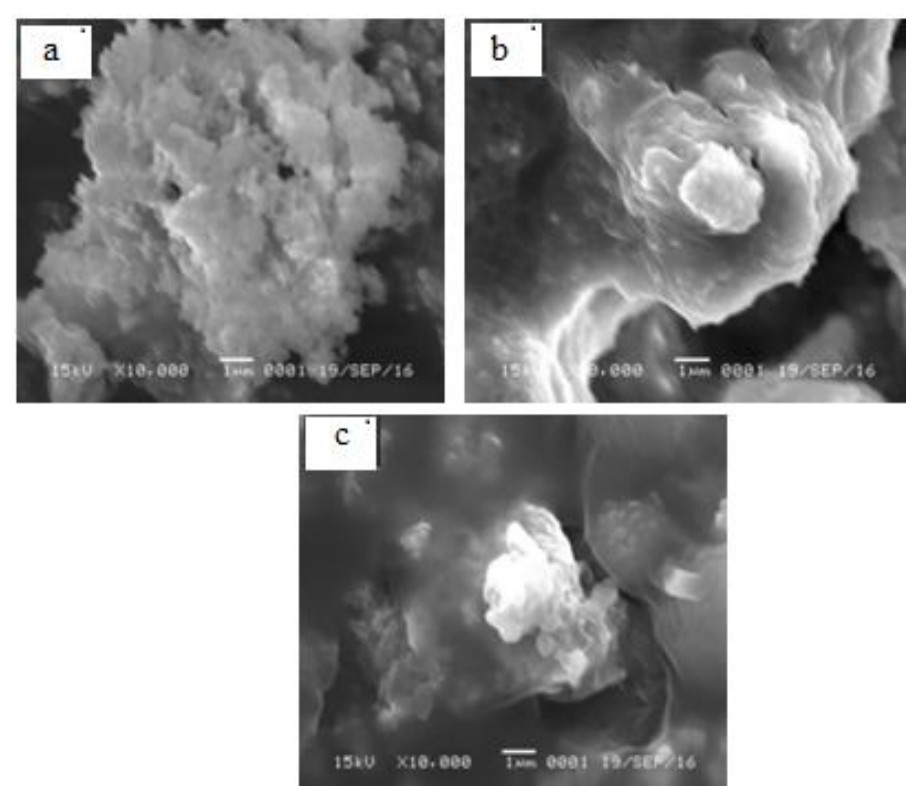

Gambar 2 Morfologi permukaan (a) sampel 1, (b) sampel 2, dan (c) sampel 3

Berat molekul PEG mempengaruhi morfologi permukaan. Jika berat molekul PEG kecil maka partikel-partikel yang terbentuk lebih homogen, sedangkan jika berat molekul PEG besar, maka semakin banyak jumlah rantai PEG yang melapisi permukaan partikel $\mathrm{MgO}$, sehingga akan menghambat pertumbuhan partikel (Wang dan Jiang, 2009).

\section{KESIMPULAN}

Berdasarkan penelitian yang telah dilakukan, maka dapat disimpulkan bahwa penggunaan PEG berpengaruh terhadap morfologi nanopartikel MgO. Pada sampel 1 morfologi permukaan partikel lebih homogen, sedangkan sampel 2 dan sampel 3 terdapat bongkahanbongkahan akibat aglomerasi antar partikel. Berdasarkan hasil XRD, terlihat bahwa semakin besar berat molekul PEG, maka semakin besar persentase puncak $\mathrm{MgO}$ yang dihasilkan. Ukuran kristal $\mathrm{MgO}$ yang didapatkan pada sampel 1, sampel 2, dan sampel 3 berturut-turut yaitu $66,76 \mathrm{~nm}, 74,15 \mathrm{~nm}$, dan $66,79 \mathrm{~nm}$, sehingga ukuran kristal sampel 1 dan sampel 3 sama. Hasil XRD dan SEM menunjukkan bahwa dengan penambahan PEG mempengaruhi kehomogenan partikel dan ukuran kristal, tetapi tidak mengurangi aglomerasi antar partikel.

\section{DAFTAR PUSTAKA}

Abdullah, M., Pengantar Nanosains, (Institut Teknologi Bandung, Bandung, 2009)

Alpionita, P. dan Astuti, Jurnal Fisika Unand, Vol.4, No.2 (2015), hal.167-172.

Ganaphati, K.R., Ashok, CH., Venkateswara, K.R. dan Shilpa, C.CH., International Journal of Science and Research (IJSR), (2013), hal. 43-46.

Klabunde, K.J., Nanoscale Material in Chemistry, (John Wiley \& Sons, Inc, New York, 2001), hal. 1-18.

Meenakshi, S.D., Rajarajan, M., Rajendran, S., Kennedy, R. dan Brindha, G., Elixir Nanotechnology, (2012), hal. 10618-10620.

Wang, L.L. dan Jiang, J.S., Preparation of $\mathrm{Fe}_{3} \mathrm{O}_{4}$ Sperical Nanoporous Particles Facilitated by Polyethylene Glycol 4000, Nanoscale Res Lett 4, 1439-1446 (2009).

Witjaksono, A.,"Karakterisasi Nanokristalin ZnO Hasil Presipitasi Dengan Perlakuan Pengeringan, Anil dan Pasca-Hidrotermal”, Tesis, Universitas Indonesia, 2011. 